Editorial

\title{
Effect of antenatal breastfeeding counselling done in-hospital prior to delivery on breast feeding outcomes amongst mothers admitted at a tertiary care hospital in middle India
}

\author{
Phuljhele S. ${ }^{1}$, Rathia S.K. ${ }^{2}$, Chandrakar A. ${ }^{3}$ \\ ${ }^{1}$ Dr. Sharja Phuljhele, Professor and Head, ${ }^{2}$ Dr. Santosh Kumar Rathia, Assistant Professor; ${ }^{3}$ Dr. Ankita Chandrakar, \\ Post-Graduate student; all authors are affiliated to Department of Pediatrics, Pt. J. N. M. Medical College, Raipur, CG, \\ India.
}

Correspondence Authors: Dr. Santosh Kumar Rathia, Assistant Professor; Department of Pediatrics, Pt. J. N. M. Medical College, Raipur, CG, India. Email: drsantoshrathia84@gmail.com, drankita2206@gmail.com

\begin{abstract}
Introduction: Antenatal counseling and postnatal support aided early initiation and exclusive breastfeeding ensure optimum childhood nutrition and reduced morbidity/mortality. Objective: To evaluate the effect of immediate antenatal counselling on breastfeeding outcomes in terms of early initiation and establishment. Methods: This study was conducted over one-year period including pregnant women with term gestation admitted for anticipated delivery and excluding mothers delivering baby with orofacial or multiple anomalies or babies who required hospitalization within 24 hours. All expectant mothers (irrespective of prior antenatal counseling status) were counseled before delivery after hospitalization. Controls were those who could not be counseled before delivery due to reasons like emergency delivery/LSCS. Sample size- taking power of $80 \%$ with $95 \%$ C.I., we required 1884 subjects. Data collected on Microsoft Excel sheet was analysed using SSPS software. Results: Out of 1884 mothers enrolled irrespective of prior antenatal breastfeeding counseling, 1328 cases $(70.4 \%)$ were counseled prior to delivery and rest 556(29.6\%) could not be counseled (considered as control). Among freshly counseled mothers, 65.5\% initiated early (within 1hr after NVD or within 4 hours of LSCS) and $89 \%$ established adequate breastfeeding within 24 hours compared to $46 \%$ early initiation (EI) and 54\% early establishment (EE) in non-counseled group. Mean hours taken foradequately established breastfeeding was also lower in subjects who received immediate counseling prior to delivery. Conclusion: Antenatal breastfeeding counseling including that done in-hospital prior to deliveryhelps in early initiation and establishment of breastfeeding.
\end{abstract}

Key words: Breastfeeding, Antenatal counseling, Early initiation, Establishment, Exclusive

\section{Introduction}

Breast milk is considered as the ideal food for newborns and infants. The two most common childhood illnesses responsible for childhood mortality are diarrhea and pneumonia. Breast milk contains antibodies that help to protect infants from such infections and thus is an effective means of reducing infant illness and mortality at the community level. Breast milk also helps in quick recovery in case of illnesses [1]. Breast milk contains appropriate amount of nutrients including protein, carbohydrate, fat, minerals and vitamins required for the optimal growth of the infant [2]. Along with short-term benefits, breastfeeding has some long-term benefits too.

Manuscript received: $8^{\text {th }}$ May 2018

Reviewed: $18^{\text {th }}$ May 2018

Author Corrected: $25^{\text {th }}$ May 2018

Accepted for Publication: $30^{\text {th }}$ May 2018
A systematic review conducted by WHO suggests that there is causal effect of breastfeeding on Intelligence Quotient (IQ). Longer duration of breastfeeding may provide some protection against obesity and type-II diabetes mellitus [3].

Exclusive breast-feeding means that the infant receives only breast milk and no other solid or liquid diet including water during first six month of infancy, with the exception of oral rehydration solution, or drops/syrups of vitamins, minerals or medicines [4]. Despite the fact that the overall rate of exclusive breastfeeding is not high, a study by Mullany et al indicated that there has been a lot of improvement in exclusive breastfeeding in between 1990 to 2004 [5]. Yet again another data from NFHS-3(2005-06) showed 


\section{Editorial}

that the recommendations on breastfeeding is not being achieved optimally, which is highly influenced by the socio-demographic determinants, feeding practices on the maternity wards, education level of parents and number of children [6]. Similarly, other factors like lower breastfeeding knowledge, attitudes towards breast feeding and number of children also affected the confidence regarding breastfeeding among mothers [7].

Breastfeeding counseling is the process of counseling the women to exclusively breastfeed their baby so as to enhance positive breastfeeding outcome. Counseling is very important in developing mothers' confidence also $[8,9]$. Effective counseling and adequate information about breastfeeding received during pregnancy period influences the initial breastfeeding intentions resulting in the favorable and longer breastfeeding outcome $[10,11]$.

Most of the previous studies on antenatal breastfeeding counseling have included usually routine counseling during $2^{\text {nd }}$ and/or $3^{\text {rd }}$ trimesters, but in our study we tried to include in-hospital counseling intervention prior to delivery to assess the impact of immediate antenatal counseling and also that after both occasionsimmediate plus past counseling.

\section{Material and Method}

This prospective observational study was conducted over one year period including all pregnant women with term gestation admitted in thedepartment of Obstetrics and Gynecology at Dr Bhim Rao Ambedkar Memorial Hospital associated withPt JNM Medical College, Raipur (CG, India) for anticipated delivery and excluding mothers delivering baby with orofacial or multiple anomalies or babies who required hospitalization within 24 hours. All expectant mothers (irrespective of prior antenatal counseling status) were counseled before delivery after hospitalization. Controls were those who could not be counseled before delivery due to reasons like precipitous labour/emergency delivery/caesarian. Sample size- as calculated by taking power of $80 \%$ with $95 \%$ C.I. using G-Star power software, we required total 1884 subjects. Data collected on Microsoft Excel sheet was analysed using SPSS $\left(\right.$ for windows ${ }^{\mathrm{TM}}$ Version 17, IBM $^{\mathrm{TM}}$ Corp NY and Microsoft excel ${ }^{\mathrm{TM}}$ 2007, Microsoft ${ }^{\circledR}$ Inc USA.
Data Collection and study methodology: Prior consent was obtained from all participants/ eligible mothers. Antenatal breastfeeding counseling was done by us preferably within 6 hours before delivery to all expectant mothers (irrespective of prior ANC counseling status) explaining benefits of early initiation and exclusive breastfeeding and correct methods of feeding by using posters, pictures and written counseling materials (from WHO training material). Mothers whose baby needed NICU admission within 24 hours of birth were excluded from study (even if counseled as study subject).

Outcome Measures: Initiation of breastfeeding within first hour after normal delivery or within four hours after Caesarian sectionwas considered as -'Early Initiation', while establishment of adequate breast feeding within 24 hours of delivery was taken as 'Early Establishment'.

Primary outcome was evaluated as difference on frequency of early initiation and established breast feeding in two study groups (in-hospital counseled and non-counseled before delivery). Another major objective was to detect association between same outcomes (early initiation \& early establishment) and counseling at both occasions (immediate prenatal plus previous ANC visits).

Secondarily, we calculated the percentage of mothers who initiated breastfeeding timely (even at least by 24 hours of delivery) and the mean time required for establishment of breastfeeding with and without predelivery breastfeeding counseling in both occasions (immediate and past ANC visits).

\section{Statistical Analysis}

- Data was expressed as percentage and mean \pm S.D.

- Student's t test was used to check the significance of difference between two parameters in parametric data and Mann Whitney $U$ test was used to check the significance of difference in non parametric data

- Fischer's exact test or Chi square test was used to analyze the significance of difference between frequency distribution of the data.

- $\mathrm{P}$ value $<0.05$ was considered for statistical significance.

\section{Results}

We could recruit total 1884 mothers during the study period. Demographically, maximum number of subjects were in the age group $18-30$ years $(98.8 \%)$ and $1.1 \%$ subjects were $>30$ years, while only $0.1 \%$ mothers were $<18$ years group. Common educational qualification in our literate subjects was upto high school (in 25.3\%) and higher secondary (in $19.3 \%$ ), but maximum of mothers we had enrolled were illiterate (33.8\%). More than half (52 \%) subjects were 
housewives; while $18.3 \%$ subjects were health care workers by occupation, $17.6 \%$ subjects were labourer and $8.6 \%$ study subjects were involved in farming. Maximum number of subjects were having $2^{\text {nd }}$ gravida $(35.2 \%)$ during this study followed by primigravida $(30.5 \%)$ and $3^{\text {rd }}$ gravida $(26.4 \%)$. Majority of our subjects were primi and $2^{\text {nd }}$ gravida, who actually need counseling more than mothers having multiple child birth and breastfeeding experience with/without repeated hospital visit. Pre-counseling knowledge regarding breast feeding benefits and practices was found to be satisfactory in 67\% mothers, however lack of this knowledge was evident in 33\% mothers. Among ourstudy subjects, 95.5\% mothers showed positive attitude towards breast feeding while $4.5 \%$ had pre-counseling negative attitude too. Normal vaginal delivery occurred in $52.5 \%$ subjects while $47.5 \%$ subjects needed to undergo Caesarean/LSCS. Out of total 1884 singleton babies born to our study subjects, percentage of male among babies born was marginally high $(51.1 \%)$ compared to $48.8 \%$ female babies.

Following were major observations in our study- (represented here as tables followed by text):

Table-1: In-hospital Breastfeeding counseling prior to delivery.

\begin{tabular}{|c|c|c|}
\hline Breastfeeding counseling prior to delivery (immediate/in-hospital) & Frequency & Percent \\
\hline YES (study group) & $\mathbf{1 3 2 8}$ & $\mathbf{7 0 . 4}$ \\
\hline NO (control group) & 556 & 29.6 \\
\hline Total subjects & 1884 & 100.0 \\
\hline
\end{tabular}

Breastfeeding counseling immediately prior to delivery was done in $70.4 \%$ of subjects, however no such in-hospital counseling could be performed in $29.6 \%$ enrolled mothers. Out of our study subjects, $35 \%$ were first timecounseled by us in-hospital during this delivery only and rest $35.4 \%$ of total subjects received our immediate prenatal counseling as a second or repeat occasion.

Table-2: Prior antenatal breastfeeding-counseling status.

\begin{tabular}{|c|c|c|}
\hline $\begin{array}{c}\text { Prior antenatal breastfeeding-counseling status(during previous ANC visits or } \\
\text { during 2nd and/or3rd trimester) }\end{array}$ & Frequency & Percent \\
\hline NO & 1134 & 60.2 \\
\hline YES & $\mathbf{7 5 0}$ & $\mathbf{3 9 . 8}$ \\
\hline Total & 1884 & 100.0 \\
\hline
\end{tabular}

Around $40 \%$ of all mothers enrolled were already counselled during $2^{\text {nd }}$ and/or $3^{\text {rd }}$ trimesterof present pregnancy or ever before during previous ANC visits, but above $60 \%$ had no prior antenatal counselling in our subjects.

Table-3: Early Breastfeeding initiation within 1 hour after NVD or $4 \mathrm{hr}$ of LSCSin all study subjects

\begin{tabular}{|c|c|c|}
\hline Early Breastfeeding initiation (within 1 hr after NVD or 4hr of LSCS) in all subjects & Frequency & Percent \\
\hline YES & $\mathbf{1 2 3 4}$ & $\mathbf{6 5 . 5}$ \\
\hline NO & 650 & 35.5 \\
\hline Total & 1884 & 100.0 \\
\hline
\end{tabular}

Early breastfeeding initiation within 1 hour of NVD or within 4hr of LSCS (timely initiation) was observed in $65.5 \%$ subjects, however more than a third subject $(35.5 \%)$ had delayed initiation.

Table-4: Breastfeeding established within 24 hoursof delivery (among all study subjects)

\begin{tabular}{|c|c|c|}
\hline Breastfeeding established within 24hrs of delivery & Frequency & 14.2 \\
\hline NO & 267 & $\mathbf{8 5 . 8}$ \\
\hline YES & $\mathbf{1 6 1 7}$ & 100.0 \\
\hline Total & 1884 & Percent \\
\hline
\end{tabular}

In this study, $85.8 \%$ subjects could establishadequate breast feeding within 24 hour of delivery, while it was delayed beyond 24 hours in $14.2 \%$ of subjects. 
Editorial

Table-5: Breast feeding established by duration (in Hours) in all subjects

\begin{tabular}{|c|c|c|}
\hline Breastfeeding established by duration (in Hours) & Frequency & Percent \\
\hline$</=12$ & $\mathbf{9 6 1}$ & $\mathbf{5 1 . 0}$ \\
\hline $\mathbf{1 3 - 2 4}$ & $\mathbf{6 5 9}$ & $\mathbf{3 5 . 0}$ \\
\hline$>24$ & 264 & 14.0 \\
\hline Total & 1884 & 100.0 \\
\hline
\end{tabular}

More than $50 \%$ mothers couldestablish feedingin $<12 \mathrm{hrs}$ and $86 \%$ of all mothers established it within 24 hours of childbirth. Only $14 \%$ of all subjects had delayed establishment of breastfeeding.

Table-6: Association between Early Breastfeeding- Initiation and immediate in- hospital BF counseling prior to delivery.

\begin{tabular}{|c|c|c|c|}
\hline \multirow{2}{*}{$\begin{array}{c}\text { Early Breastfeeding- Initiation } \\
\text { (within 1 hr after NVD or 4hr of LSCS) }\end{array}$} & \multicolumn{2}{|c|}{ In-hospital breastfeeding counseling prior to delivery } & Total \\
\hline \multirow{2}{*}{ NO } & NO & 350 & 650 \\
\hline & 300 & $\mathbf{2 6 . 4 \%}$ & $34.5 \%$ \\
\cline { 2 - 4 } & $\mathbf{5 4 . 0 \%}$ & 978 & 1234 \\
\hline YES & 256 & $\mathbf{7 3 . 6 \%}$ & $65.5 \%$ \\
\cline { 2 - 4 } & $\mathbf{4 6 . 0} \%$ & $\mathbf{1 3 2 8}$ & 1884 \\
\hline Total & 556 & $100.0 \%$ & $100.0 \%$ \\
\hline
\end{tabular}

Significant association was found between early initiation of breastfeeding and in-hospital counseling as analyzed by Fisher Exact test $(\mathrm{p}=0.0005)$ indicating higher rate of timely initiation in subjects counseled prior to delivery irrespective of previous antenatal counseling and knowledge status.

Table-7: Association of Early Breastfeeding-initiation with frequency of ANC Visits

\begin{tabular}{|c|c|c|c|}
\hline No. of ANC Visits & \multicolumn{2}{|c|}{ Early Breastfeeding- Initiation } & \multirow{2}{*}{ Total } \\
\hline \multirow{2}{*}{$<=3$} & NO & YES & 1234 \\
\cline { 2 - 4 } & 444 & $\mathbf{7 9 0}$ & $65.6 \%$ \\
\hline \multirow{2}{*}{$>3$} & $68.4 \%$ & $\mathbf{6 4 . 1} \%$ & 647 \\
\cline { 2 - 4 } & 205 & $\mathbf{4 4 2 . 9 \%}$ & $34.4 \%$ \\
\hline \multirow{2}{*}{ Total } & $31.6 \%$ & $\mathbf{1 2 3 2}$ & 1881 \\
\cline { 2 - 4 } & 649 & $\mathbf{1 0 0 . 0} \%$ & $100.0 \%$ \\
\hline
\end{tabular}

Significant association between above two parameters was found (Exact test significant, $\mathrm{p}$ value $=0.035$ ) indicating higher frequency of timely initiation of BF in subjects with more ANC visits.

Table-8: Association of Early Breastfeeding-Initiation withCounseling at both occasions (Immediate/In-hospital and prior antenatal visits).

\begin{tabular}{|c|c|c|c|}
\hline \multirow{2}{*}{ Early Breastfeeding- Initiation } & \multicolumn{2}{|c|}{ Counseling at both occasion } & \multirow{2}{*}{ Total } \\
\hline \multirow{2}{*}{ NO } & NO & YES & 650 \\
\hline & 591 & 59 & $34.5 \%$ \\
\cline { 2 - 4 } & $\mathbf{4 6 . 3 \%}$ & $\mathbf{9 . 7 \%}$ & 1234 \\
\hline YES & 685 & 549 & $65.5 \%$ \\
\cline { 2 - 4 } & $\mathbf{5 3 . 7 \%}$ & $\mathbf{9 0 . 3} \%$ & 1884 \\
\hline Total & 1276 & $100.0 \%$ & $100.0 \%$ \\
\hline
\end{tabular}


Editorial

Significant association was found between two parameters in both Pearson chi-square test as well as Fischer's Exact test with 2-sided significance ( $\mathrm{p}=0.000)$ indicating higher timely initiation of BF rate in subjects counseled in two or more occasions (immediately prior to delivery and previous antenatal visits).

Table-9: Association of Breastfeeding-Establishment within 24hours of delivery with Counseling at both occasions

\begin{tabular}{|c|c|c|c|}
\hline \multirow{2}{*}{ Established breastfeeding within 24 of delivery } & \multicolumn{2}{|c|}{ Counseling at both occasions } & \multirow{2}{*}{ Total } \\
\hline \multirow{2}{*}{ NO } & NO & 85 & 267 \\
\hline & 182 & $\mathbf{1 4 . 0} \%$ & $14.2 \%$ \\
\cline { 2 - 4 } & $\mathbf{1 4 . 3 \%}$ & 523 & 1617 \\
\hline YES & 1094 & $\mathbf{8 6 . 0} \%$ & $85.8 \%$ \\
\cline { 2 - 4 } & $\mathbf{8 5 . 7 \%}$ & 608 & 1884 \\
\hline
\end{tabular}

Association of timely breastfeeding-establishment by $24 \mathrm{hrs}$ and counseling at both occasions was performed using Chi square test but no significant association was detected.

Table-10: Comparison of time taken in hours for established breastfeeding amongst subjects who were counseled at both occasions (immediate plus past antenatal).

\begin{tabular}{|c|c|c|c|c|c|c|c|}
\hline $\begin{array}{c}\text { Time taken to have established } \\
\text { breastfeeding (in Hrs) }\end{array}$ & & $\mathrm{N}$ & $\begin{array}{c}\text { Mean } \\
\text { (Hours) }\end{array}$ & $\begin{array}{c}\text { Std. } \\
\text { Deviation }\end{array}$ & $\begin{array}{c}\text { Std. Error } \\
\text { Mean }\end{array}$ & $\mathrm{T}$ & $\mathrm{P}$ value \\
\hline Counseling at both occasions & NO & 1276 & 21.3009 & 12.23971 & .34265 & .309 & .757 \\
\cline { 2 - 9 } & YE & 608 & 21.1184 & 11.84020 & .48018 & & \\
\hline
\end{tabular}

Analysis was performed using student's unpaired t test. Although the difference failed to reach statistical significance,the breastfeeding-establishment time was found to be lower in subjects who received counseling in more than one occasion or got counseling awareness in multiple sessions including fresh in-hospital counseling and breastfeeding support.

\section{Discussion}

While breast feeding practices in India have improved over time, some of harmful practices are still continuing like use of prelacteals, non-use of colostrum, early top feeding and weaning etc. In this study, it was investigated whether antenatal breastfeeding counseling prior to delivery improves outcomes of breast feeding in terms of early initiation, establishment of breast feeding, and role of various other factors affecting timely initiation/ establishment/exclusivity of breastfeeding.

Out of 1884 mothers, maximum were in age group 18$30 \mathrm{yrs}(98.8 \%)$ with only $0.1 \%$ being under $18 \mathrm{yrs}$ amongst our study subjects. Maximum number of subjects had second gravida (35.2\%) followed by primigravida $(30.5 \%)$ and rest were already multipara mothers. One third of mothers were illiterate $(33.8 \%)$, while about $45 \%$ were educated upto high or higher school. Over half of subjects were housewives, around $25 \%$ were labourer or farming laborers by occupation, and $18.3 \%$ subjects were themselves health care workers. Most of them belonged to lower socioeconomic status (>58\%). Nearly $60 \%$ subjects were from joint families. Normal institutional vaginal delivery was performed in $52.5 \%$ subjects, while $47.5 \%$ of mothers delivered their baby after elective LSCS. Percentage of male babies born was marginally higher ( $51 \%$ versus $49 \%$ females) in this study group.

More than $3 / 4^{\text {th }}$ subjects were ANC booked and around $20 \%$ mothers had never attended ANC clinic, most being primipara. Prior antenatal counseling during $2^{\text {nd }}$ or $3^{\text {rd }}$ trimester was already received by only $40 \%$ subjects, while rest of $60 \%$ were never formally counseled ever before. Immediate breastfeeding counseling before delivery could be performed in $70.4 \%$ of our subjects.

Early initiation of breastfeeding (within 1 hour of NVD and within 4 hrs of LSCS) was observed in $65.5 \%$ of all 
Editorial

subjects; however, as more as $85 \%$ of mothers could initiate breastfeeding within 24 hours of birth and at least by this time limit, exclusive breast feeding can be more assured. In context of early establishment of breastfeeding, overall as high as $86 \%$ of subjects could establish adequately within 24 hours, although more than half $(51 \%)$ mothers established it even earlier within $</=12$ hours of child birth, that was another rewarding observation in this study conducted in a so called backward state in middle India.

Mean time of adequately established breastfeeding in our study was $21.2 \mathrm{hrs}$, with no statistically significant difference between counseled and non-counseled groups.

Mullany et al in their study from Nepal reported that despite all (100\%) mothers adopting breastfeeding practice, the initiation of breastfeeding within one hour (only in $3.4 \%$ of mothers) and the practice of exclusive breastfeeding for adequate duration (observed in 28\%) were disappointing (i.e. $72 \%$ of the infants were partially breastfeed) [5]. The status of breastfeeding and complementary feeding practices is very dismal in India too. According to the NFHS- 3(2005-06), the initiation of breastfeeding within one hour of birth was only $24.5 \%$ [6]. However, more recent data from the DLHS3 (2007-08) shows slight improvement up toan average of $40.2 \%$ [7]. An analysis of data of 534 districts, revealed that rate of initiation of breastfeeding within an hour was between $0-29 \%$ in 138 districts, $30-49 \%$ in 197districts, $50-89 \%$ in 194 and above 90\% rate was seen only in 5 districts.

According to DLHS-3, in 485 districts exclusive breastfeeding for the first six month is below $50 \%$ [7] The NFHS-3 also reported exclusive breastfeeding up to the age of six month to be only $46.4 \%$ in India. Further analysis of age wise data also reveals that exclusive breastfeeding rapidly declines from first month to sixth month, and only about $27.6 \%$ children continue it by six month, giving a real low figure of exclusive breastfeeding [6].

Setgen et alin their study reported that timely initiation of breastfeeding was significantly associated with place of residence, educational status, institutional delivery, and post-natal advice on breast feeding. Urban mothers were more likely to initiate breastfeeding early as compared to their rural counterparts which was $73.5 \%$ and $47.3 \%$, respectively $(\mathrm{P}<0.001)$. Mothers who had formal education were 1.4 times as likely to initiate breastfeeding with in the first hour after delivery as compared to those mothers who had no formal education. Mothers who delivered in health institutions were twice as likely initiate breastfeeding as compared to those delivered at their home. Setgenalso reported that mothers counseled on postnatal period were about $52 \%$ more likely to initiate breastfeeding within the first hour of delivery [12].

Wolde et al too reported findings similar to us stating that advice given to mother on breast feeding during antenatal care visits and knowing importance of colostrum were positively associated with timely initiation of breastfeeding [13].

Association between early initiation and immediate counseling before delivery was found to be highly significant $(\mathrm{p}=0.0001)$ indicating high timely initiation in our freshly intervened/counseled group. Similarly, higher initiation rate was observed in subjects receiving counseling in both past and immediate occasions i.e. who had also been counseled during previous ANC visits before our immediate counseling $(p=0.000)$. reater number of ANC visits revealed significant association with early initiation.

Bimerev et al also reported that timely initiation of breastfeeding was significantly associated with the presence of four and more antenatal appointments during the last pregnancy [14]. Tilahun Get al reported that age of the mothers, educational status, religion, husbands' education, child sex, parity, mode of delivery, history of Antenatal care (ANC) visit, place of delivery, having information/advice on timely initiation of breast feeding during ANC visits and having information/advice on timely initiation of breast feeding (TIBF) immediately after delivery had shown association with timely or early initiation [15].

With respect to establishment of breast feeding by 24 hours, our immediate counseling alone had no significant impact, and even though counseling in two occasions (including prior antenatal and our counseling) resulted in slight lower mean time taken for established feeding $(21.1 \mathrm{hrs}$ versus 21.3 hours in counseled versus not counseled), but that was not statistically significant.

Among factors affecting our major outcomes of early initiation and established breastfeeding, only number of ANC visits and thus multiple (immediate plus past visits) counseling occasions significantly improved timely initiation rate; while feeding establishment within $24 \mathrm{hrs}$ period was favored by other factors as well like mothers' education, occupation, gravida/ parity, family type and pre-counseling knowledge about breastfeeding practice. 
On comparing with other studies, we can conclude that apart from maternal education, occupation, parity/ gravida, number of ANC visits, socioeconomic or cultural factors and previous knowledge/attitude, repeated antenatal counseling specifically along with immediate prenatal (or in-hospital)counseling before delivery can be reliably associated withappropriate timely initiation and establishment of breastfeeding.

\section{Conclusion}

Immediate in-hospital breastfeedingcounseling of mothers before delivery was associated with significantly higher rate of timely or early breastfeeding -initiation. Early initiation was observed in case of $65.5 \%$ mothers and overall $85 \%$ babies were initiated at least within 24 hrs of delivery.

Adequate number of ANC visits $(>/=3)$ showed higher rate of early initiation suggests even formal antenatal counseling sessions at multiple occasions could ensure timely initiation and early establishment of breastfeeding. Thus counseling at both occasions (prior ANC visits and immediate in-hospital counseling) may definitely improve rate of early initiation and establishment of exclusive breast feeding practices.

What this study adds to existing knowledge/practice: This study supports and strengthens the favorable outcome of repeated antenatal breastfeeding counseling in regards of early initiation and early establishment of exclusive breastfeeding along with indirect stimulation for adequate duration of exclusive as well as total breastfeeding.

Contributions by authors: Phuljhele $\mathrm{S}$ conceived and supervised the study and helped in finalizing manuscript writing. Rathia SK helped in protocol writing and conceptualization, analyzed data, prepared and finalized the manuscript; will be the principal corresponding author. Chandrakar A wrote the protocol, recruited patients and helped in data analysis and manuscript writing. The final manuscript was approved byall authors.

Acknowledgements: We acknowledge the supporting staff of department of Obstetrics \& Gynecologyand our pediatrics resident doctors who helped during breast feeding counseling and demonstration sessions, as well as helping hands of faculty staff from both departments, who routinely take care of all mothers and babies promoting early breastfeeding practice.

Funding: Nil, Conflict of interest: None initiated, Perission from IRB: Yes

\section{References}

1. Di Girolamo AM, Grummer-Strawn LM, Fein SB. Do perceivedattitudes of physicians and hospital staff affect breastfeeding decisions? Birth. 2003 Jun; 30 (2): 94-100.

2. World Health Organization. Long-term effects of breastfeeding: a systematic review [Internet]. 2013 [updated 2014 Feb 25; cited 2017 Sep 7]. Available from: http://www.who.int/maternal_child_adolescent/ documents/ breastfeeding_long_term_effects/e n

3. World Health Organization. E-Library of Evidence for Nutrition Actions (eLENA), Breast feeding exclusive breast feeding [Internet]. 2014 [updated 2014 Feb 5; cited 2017 Sep7]. Available from: http:// www. who. int/ elena/ titles/ exclusive_ breast feeding/en

4. UNICEF. Progress for children: A report card on Nutrition, 2006 Number 4 [Internet]. New York: UNICEF; 2006 [cited 2017 Sep 7]. Available from: http:// www.unicef. org/ progress for children/ 2006n4 /index_breastfeeding.html

5. Mullany LC, Katz J, Li YM, Khatry SK, LeClerq SC, Darmstadt GL, Tielsch JM. Breast-feeding patterns, time to initiation, and mortality risk among newborns in southern Nepal. J Nutr. 2008 Mar; 138 (3): 599603.

6. Government of India (GoI). MoFHW. National Family Health Survey - 3, 2005-06, India [Internet]. Mumbai: International Institute for Population Sciences (IIPS), 2005. Available from: http://www.nfhsindia.org/ nfhs3_national_report.html

7. Government of India (GoI). MoFHW. District level household and facility survey, DLHS - 3, Fact Sheets [Internet]. Mumbai:International Institute for Population Sciences (IIPS), 2007. Available from: http:// nrhmmis. nic.in/ui//DLHSIII/ dlhs08_release_1.htm\#BR

8. World Health Organization; UNICEF. Breastfeeding counselling: a training course - Director's guide [Internet].NewYork:UNICEF;1993.Available from:http: //www.who.int/maternal_child_adolescent/ documents/ pdfs/bc_directors_guide.pdf

9. Laanterä S, Pietilä AM, Ekström A, Pölkki T. Confidence in breastfeeding among pregnant women. West J Nurs Res.2012 Nov;34(7):933-51. doi: 10.1177/ 0193945910396518. Epub 2011 Jan 31. 


\section{Editorial}

10. Harlow BA. Breast feeding counseling, barriers and facilitators of lactation in the military community [monograph online]. Ipswich, MA: Uniformed Services University of the Health Sciences; 1998 [cited 2017

Sep]. Available from: CINAHL, Ipswich, MA

11. Leung AK, Sauve RS. Breast is best for babies. J Natl Med Assoc. 2005 Jul; 97(7): 1010-9.

12. Setegn T, Gerbaba M, Belachew T. Determinants of timely initiation of breastfeeding among mothers in Goba Woreda, South East Ethiopia: a cross sectional study. BMC Public Health. 2011 Apr 8;11:217. doi: 10. 1186/1471-2458-11-217.

13. Gelete BW, Addisu YK, Haile MT. Timely Initiation of Breastfeeding and Its Associated Factors among Mothers in Tiyo Woreda, Arsi Zone, Ethiopia: A Community- Based Cross Sectional Study. Clinics Mother Child Health. 2016;13(1): 221. doi:10.4172/ 2090- 7214. 1000221

14. Bimerew A, Teshome M, Kassa GM. Prevalence of timely breastfeeding initiation and associated factors in Dembecha district, North West Ethiopia: a crosssectional study. Int Breastfeed J. 2016;11:28. Published online 2016 Oct 6 . doi: 10.1186/s13006-016-0087-4

15. Tilahun G, Degu G, Azale T, Tigabu A. Prevalence and associated factors of timely initiation of breastfeeding among mothers at Debre Berhan town, Ethiopia: a cross-sectional study. International Breast feeding Journal. 2016 Oct 3; 11 (1): 27.doi:10. 1186/s 13006-016-0086-5

\section{How to cite this article?}

Phuljhele S, Rathia S.K, Chandrakar A. Effect of antenatal breastfeeding counselling done in-hospital prior to delivery on breast feeding outcomes amongst mothers admitted at a tertiary care hospital in middle India. Int J Pediatr Res. 2018;5(5):284-291.doi:10.17511/ijpr.2018.i05.08. 